\title{
Antitumor Effect of Kigamicin D on Mouse Tumor Models
}

\author{
Toru Masuda, Shunichi Ohba, Manabu Kawada, Michiyo Osono, Daishiro Ikeda, \\ Hiroyasu Esumi, Setsuko Kunimoto
}

Received: December 16, 2005 / Accepted: April 7, 2006

(C) Japan Antibiotics Research Association

\begin{abstract}
Kigamicin D is a novel anticancer agent that was identified using a new screening strategy that targets the tolerance of cancer cells to nutrient starvation $[1,2]$. Oral administration of kigamicin D was previously described to show a strong antitumor effect in human tumor xenograft models of pancreatic tumors [2]. In this paper we describe that kigamicin D shows the same selective cytotoxicity against normal human cells such as lung fibroblast and prostate stromal cells under nutrient starved condition as against cancer cells. Kigamicin D inhibited tumor cell-induced angiogenesis in a dorsal air sac assay. On the basis of these results we tested other human tumor xenograft models and transplantable syngeneic tumor models in order to determine the spectrum of activity of kigamicin D against various cancers. Kigamicin D showed a weak antitumor effect against LX-1 and DMS-273 lung cancers, but had no effect on DLD-1 colon cancers. When tested against syngeneic tumors, kigamicin D showed a weak antitumor effect against colon26, but showed augmentation of tumor growth on IMC carcinoma at a broad dosage level. Kigamicin D does not show good antitumor activity against human xenograft tumors except pancreatic tumors and murine syngeneic tumors. We found that kigamicin D has excellent antitumor effect specific to pancreatic cancers. Surprisingly, high dosage of kigamicin D increased tumor growth of IMC carcinoma by than $200 \%$. The phenomenon suggests that kigamicin D may cause some immunological response to the tumor.
\end{abstract}

T. Masuda (Corresponding author), S. Ohba, M. Kawada, M. Osono, D. Ikeda, S. Kunimoto: Numazu Bio-Medical Research Institute, Microbial Chemistry Research Center, 18-24 Miyamoto, Numazu-shi, Shizuoka 410-0301, Japan,

E-mail:masudat@bikaken.or.jp
Keywords kigamicin D, xenograft, syngeneic, IMCcarcinoma

\section{Introduction}

Human xenograft tumor models implanted in nude or scid mice have provided good insights for the therapeutic possibility of antitumor agents. In human pancreatic tumor xenograft models, tumors are thought to keep the natural characteristics of pancreatic cancers such as hypovascularity and aggressive malignant behavior despite poor blood supply. Kigamicin D showed strong antitumor effect on human tumor xenograft models of pancreatic tumors such as PANC-1, Capan-1, and MIA Paca-2 in nude or scid mice [2]. Kigamicin D also showed cytotoxicity selective to nutrient starved culture in normal cells such as fibroblasts and human prostate stromal cells as described below. The center of solid tumors is known to be hypoxic and deficient in nutrient because of it being avascular. It has been evidenced that PI3K promotes angiogenesis, and, PI3K inhibitors such as LY294002 and wortmannin have antiangiogenic activity in vivo $[5,6]$. Kigamicin D was previously described to inhibit PI3K/Akt pathway and shows antiangiogenic activity [2]. These two findings, namely the cells' response to kigamicin D under nutrient starvation and the antiangiogenesis activity of kigamicin D, prompted us to assess the antitumor spectrum of kigamicin D. We studied human tumor xenograft models other than pancreatic tumors and transplantable syngeneic tumor

H. Esumi: National Cancer Center Research Institute East, 6-5-1, Kashiwanoha, Kashiwa-shi, Chiba, 277-8577, Japan 
models. Kigamicin D did not show good antitumor activity in these models unlike in human pancreatic xenografts. Antitumor activity of kigamicin D is considered to be specific to pancreatic tumors, possible because of its hypovascularity.

\section{Materials and Methods}

\section{Preparation of Kigamicin D}

Kigamicin D was prepared by large-scale production and the purification method was modified from that previously described [1] as follows. The strain Amycolatopsis sp. ML630-mF1 was inoculated into two 30-liter jar fermenters containing 15 liters of the culture medium per jar as previously described [3]. The fermentation was performed at $30^{\circ} \mathrm{C}$ at 6 days. The culture filtrate (24 liters) was applied to a Diaion HP-20 column (Mitsubishi Chemical Co., Tokyo, 1 liter, $5.5 \times 40.5 \mathrm{~cm}$ ) and eluted with $50 \%$ acetone water. The eluate was concentrated to remove acetone and adjusted to $\mathrm{pH} 2.0$ and extracted with an equivalent volume of butylacetate. After removal of butylacetate by evaporation and drying under vacuum, the dried paste ( $4.64 \mathrm{~g}$ ) was charged on a silica gel column (Wako gel 200, Wako Pure Chemical Industries, Osaka, $206 \mathrm{~g}, 6 \times 14 \mathrm{~cm}$ ), and eluted stepwise with mixtures of $\mathrm{CHCl}_{3}$ and methanol $(50: 1,25: 1$, and $10: 1)$. The active eluate was charged onto a reverse phase ODS column (Senshu Scientific Co. Ltd., Tokyo, ODS7515-12, $480 \mathrm{ml}, 6 \times 16 \mathrm{~cm}$ ) and developed with a mixture of $40 \%$ acetonitrile and $60 \%$ water. Kigamicin A, C, D and E were separately eluted in this order. The yield and purity of each Kigamicin was as follows: Kigamicin D, 2,240 mg of $99.9 \%$ purity by HPLC analysis; Kigamicin A, $60 \mathrm{mg}$ crystals; Kigamicin C, $800 \mathrm{mg}$ of $87 \%$ purity; and Kigamicin E, $740 \mathrm{mg}$ of $87 \%$ purity. Kigamicin D was very more effectively produced in jar fermenters than in flask cultures and it was easily purified without using HPLC.

Kigamicin D was dissolved and diluted with DMSO for in vitro assay.

For oral administration, kigamicin D was dissolved at the highest concentration administered in saline solution supplemented with $10 \%$ DMSO and $0.5 \%$ Tween 80 , and stored in a refrigerator up to a week. Before administration the stock solution was diluted in saline to give the needed concentration in a $0.25 \mathrm{ml}$ solution.

\section{Cells and Culture}

Human cancer cell lines, PANC-1 (pancreatic cancer) and DLD-1 (colon cancer), and DMS-273 (lung cancers) were obtained from American Type Culture Collection and European Collection of Cell Cultures, respectively. They were maintained in Dulbecco's modified Eagle's medium (DMEM) (Nissui Pharmaceutical Co. Ltd., Tokyo) supplemented with $10 \%$ fetal bovine serum (FCS) (Tissue Culture Biologicals, CA, USA or Vitromex, Germany). LX1 (lung cancer) was kindly supplied by Japanese Foundation for Cancer Research, Tokyo and maintained in RPMI1640 (Gibco, Invitrogen Co., CA, USA) supplemented with 10\% FCS and $100 \mathrm{units} / \mathrm{ml}$ penicillin $\mathrm{G}, 100 \mu \mathrm{g} / \mathrm{ml}$ streptomycin. Murine colon 26 cells were maintained in RPMI1640 (Gibco, Invitrogen Co., CA, USA) supplemented with 10\% FCS and $100 \mathrm{units} / \mathrm{ml}$ penicillin $\mathrm{G}, 100 \mu \mathrm{g} / \mathrm{ml}$ streptomycin. IMC carcinoma cells were maintained by a serial transplantation i.p. weekly in $\mathrm{CDF}_{1}$ mice. Normal human lung fibroblast (NHLF) cells and normal human prostate stromal $(\mathrm{PrS})$ cells were from BioWhittaker Inc. (Walkerville, MD, USA). NHLF was maintained in FGM-2 BulletKit (BioWhittaker Inc. (Walkerville, MD, USA). PrSC was maintained in DMEM supplemented with $10 \%$ FBS, 100 units $/ \mathrm{ml}$ penicillin $\mathrm{G}, 100 \mu \mathrm{g} / \mathrm{ml}$ streptomycin, ITH $(5 \mu \mathrm{g} / \mathrm{ml}$ insulin, $5 \mu \mathrm{g} / \mathrm{ml}$ transferrin and $1.4 \mu \mathrm{M}$ hydrocortisone) and $5 \mathrm{ng} / \mathrm{ml}$ basic-FGF.

\section{In Vitro Assay of Selective Cytotoxicity under Nutrient- deprived Condition}

Killing activity against PANC-1 cells under a nutrient starved condition was determined by comparing cell survival after 24 hours incubation in nutrient deprived medium (NDM) with cell survival in DMEM - 10\% FCS culture as previously described [1, 2]. NDM was composed of only electrolytes and vitamins found in the composition of DMEM as following: $\mathrm{CaCl}_{2}\left(2 \mathrm{H}_{2} \mathrm{O}\right), 265 \mathrm{mg} / \mathrm{ml} ; \mathrm{Fe}$ $\left(\mathrm{NO}_{3}\right)_{3}\left(\mathrm{H}_{2} \mathrm{O}\right), 0.1 \mathrm{mg} / \mathrm{liter} ; \mathrm{KCl}, 400 \mathrm{mg} / \mathrm{ml} ; \mathrm{MgSO}_{4}\left(7 \mathrm{H}_{2} \mathrm{O}\right)$, $200 \mathrm{mg} /$ liter; $\mathrm{NaCl}, 6400 \mathrm{mg} /$ liter; $\mathrm{NaHCO}_{3}, 700 \mathrm{mg} /$ liter; $\mathrm{NaHPO}_{4}, 125 \mathrm{mg} /$ liter; phenol red, $15 \mathrm{mg} /$ liter; $25 \mathrm{mM}$ HEPES buffer $\mathrm{pH}$ 7.4; and MEM vitamin solution (Life technologies, Inc., Rockville, MD). Less than $1 \mu \mathrm{l}$ of kigamicin D solution or DMSO was added to each culture of $100 \mu \mathrm{l}$. After 24 hours treatment cell viability was evaluated by incubation for 3 hours with DMEM containing 10\% Alamar Blue solution (Serotec Ltd., UK) [3] after PBS washing and measurement of fluorescence at $590 \mathrm{~nm}$ excited by $544 \mathrm{~nm}$ using Labsystems Fluoroscan II (Dainippon Seiyaku, Osaka).

\section{Angiogenesis}

Tumor cell-induced angiogenesis in a dorsal air sac (DAS) assay was performed in mice to examine the effect of kigamicin D on the angiogenic response triggered by S-180 cells, according to the method described by Oikawa et al. [4]. Briefly, both sides of a Millipore ring were covered 

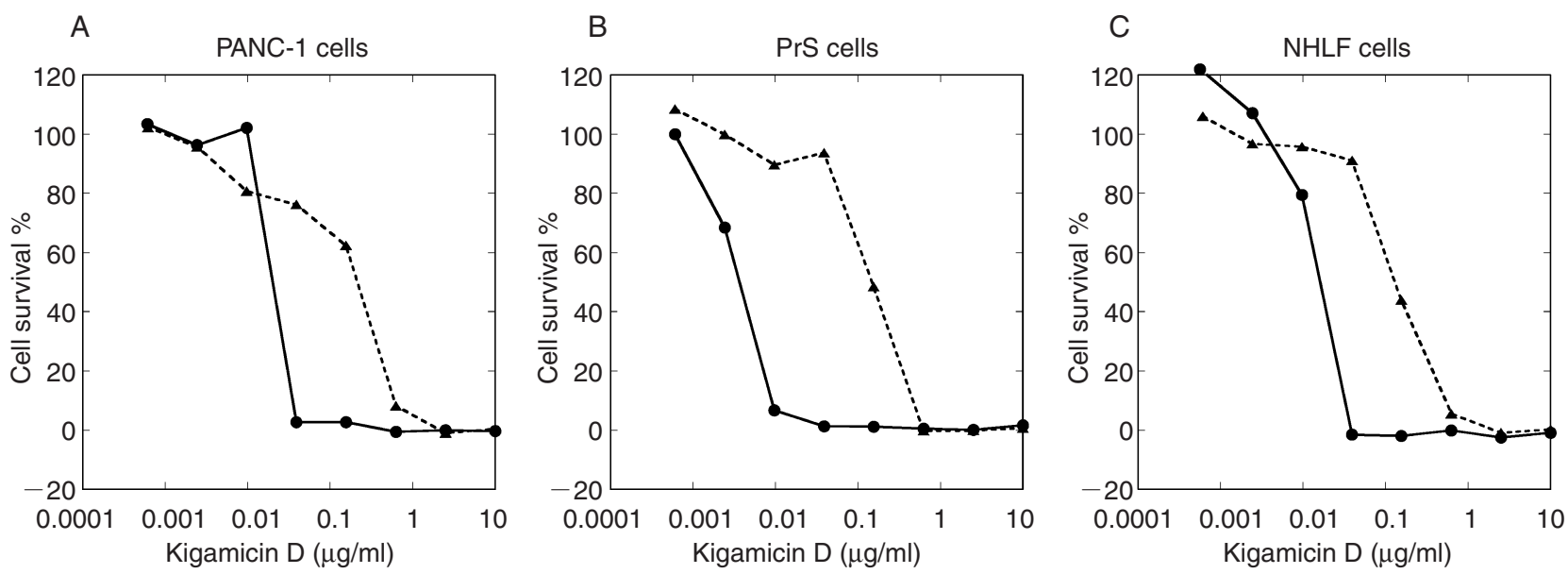

\begin{tabular}{|l|ll|c|}
\hline \multirow{2}{*}{ Cells } & \multicolumn{2}{|c|}{$I C_{50}(\mu \mathrm{M})$} & \multirow{2}{*}{$\begin{array}{c}\text { Ratio } \\
\text { DMEM/NDM }\end{array}$} \\
\cline { 2 - 3 } & NDM & DMEM & \\
\hline PANC-1 & 0.0207 & 0.224 & 10.8 \\
PrS & 0.0038 & 0.154 & 40.8 \\
NHLF & 0.0169 & 0.140 & 8.26 \\
\hline
\end{tabular}

Fig. 1 Effects of kigamicin D on PANC-1 and normal (PrS and NHLF) cells.

PANC-1 (A), PrS (B) and NHLF (C) cells were treated by kigamicin D for 24 hours under DMEM - 10\% FCS (DMEM, broken lines) or nutrient deprived medium (NDM, solid lines). Cell survival after 24 hours treatment was determined by Alamar Blue assay. IC ${ }_{50}$ values given were summarized in D.

with Millipore filters of $0.45-\mu \mathrm{m}$ pore size, and the resulting Millipore chamber was filled with a suspension of S-180 cells $\left(2 \times 10^{7}\right.$ cells $)$ in $0.15 \mathrm{ml}$ of PBS. The chamber containing S-180 cells was implanted into the preformed air sac in the dorsum of anesthetized $(50 \mathrm{mg} / \mathrm{kg}$ pentobarbital, i.p) female ICR mice. The animals were divided into six groups composed of 6 mice for each group. Drugs were orally administered from day 1 to day 4 . On day 5 , the implanted chambers were removed from the subcutaneous fascia of treated mice, and then black rings of the same inner diameter as the Millipore rings were placed on skins at the sites exposed to direct contact with the chamber. The angiogenic response was assessed with dissecting microscope photographs by determining the number of newly formed blood vessels that were more than $3 \mathrm{~mm}$ in length within the area marked by the black ring.

\section{Antitumor Activity In Vivo}

Female BALB/c nu/nu (-), BALB/c and $\mathrm{CDF}_{1}$ mice were purchased from Charles River Japan, Inc., Yokohama and maintained in a specific pathogen-free barrier facility, and provided with sterile food ad water ad libitum. Tumor cells were washed and suspended with Hank's balanced salt solution (Gibco, Invitrogen Co., CA, USA). Six weeks old mice were transplanted with $0.1 \mathrm{ml}$ of the tumor cells subcutaneously at groin as described in detail in the legends for each experiment. Kigamicin D was administered 5 days/week by oral administration after tumor grew around $6 \mathrm{~mm}$ diameters. Antitumor activity was monitored by measuring tumor volume and determined by tumor weight on the last day of each experiment. Tumor volume was calculated as follows: tumor volume $\left(\mathrm{mm}^{3}\right)=$ length $(\mathrm{mm}) \times$ width $(\mathrm{mm})^{2} \times 0.5$. The ratio of mean tumor weight of treated group to that of control group $(\mathrm{T} / \mathrm{C} \%)$ was calculated.

\section{Statistical Analysis}

All results were expressed as means \pm S.D. Statistical comparisons were made using Student's $t$ test after analysis of variance. The results were considered to be significantly different if $P$ value $<0.05$.

\section{Results and Discussion}

\section{Effect on Normal Cells In Vitro}

As shown in Fig. 1, kigamicin D showed selective cytotoxicity against nutrient-starved normal human cells 


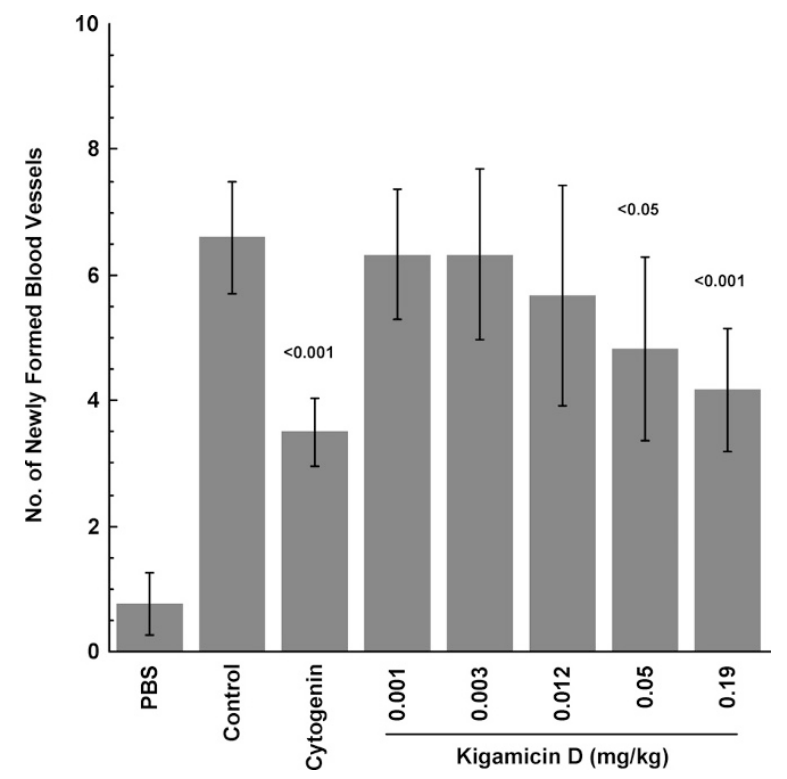

Fig. 2 Inhibitory activity of kigamicin D on the angiogenic response induced by S-180 cells.

PBS and the other groups were implanted with a chamber containing PBS alone, and S-180 cells $\left(2 \times 10^{7}\right.$ cells/chamber), respectively. Kigamicin D $(0.001,0.003,0.012,0.05$, and $0.19 \mathrm{mg} / \mathrm{kg})$ and cytogenin $(100 \mathrm{mg} / \mathrm{kg})$ as a positive control were orally administered on day 1, 2, 3 and 4 . On day 5 newly formed blood vessels were evaluated as described "Materials and Methods". P values were calculated for Control.

such as lung fibroblast and prostate stromal cells. This cytotoxic effect is similar to that observed with PANC-1 cells.

These results led to the hypotheses that kigamicin D may show effect on other solid tumor beyond pancreatic cancers because nutrient deprivation and avascular tissue is commonly found in many tumors types.

\section{Inhibition of Angiogenesis}

Kigamicin D inhibits PI3K/Akt pathway as previously described [2]. It has been shown that PI3K promotes angiogenesis, and LY294002 and wortmannin, PI3K inhibitors, have antiangiogenic activity in vivo $[5,6]$. Effect of kigamicin D on angiogenesis was determined using DAS assay. As shown in Fig. 2, kigamicin D suppressed S-180 cell-induced angiogenesis in a dose dependent manner. In human pancreatic tumors kigamicin D did not inhibit tumor angiogenesis by immunohistochemical staining using antiCD30 antibody [2]. Growth of solid tumors depends on angiogenesis, the process by which new blood vessels develop from the endothelium of a pre-existing vasculature. Many key players have been identified, but basic mechanisms have been unclear. Various mechanisms may work all

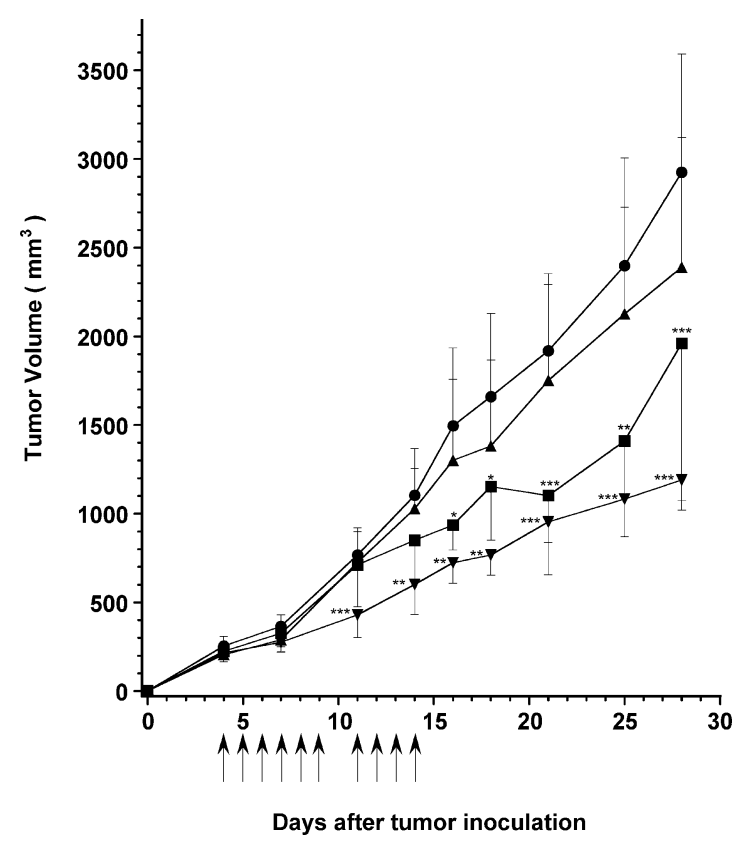

Fig. 3 Effect of kigamicin D on $L X-1$ tumor in nude mice.

BALB/c nu/nu female mice were inoculated subcutaneously with $5 \times 10^{6}$ human small cell lung carcinoma LX-1 cells on day 0 . Kigamicin $D$ was administered orally daily from day 4 to day 14 except day 10 . As a positive control, adriamycin $(2.5 \mathrm{mg} / \mathrm{kg})$ was administered intraperitoneally according to the same schedule.

-, Control (none); $\mathbf{\Delta}$, kigamicin $0.75 \mathrm{mg} / \mathrm{kg}$; 口, kigamicin $0.19 \mathrm{mg} / \mathrm{kg} ; \quad \nabla$, adriamycin $2.5 \mathrm{mg} / \mathrm{kg} ; \quad * p<0.05 ; \quad * * p<0.01$; $* * * p<0.001 ; v s$. control.

together in the same tumor or may be selectively involved in a specific tumor type or host environment. Based on the similar effect of kigamicin D on normal cells and pancreatic cells and inhibition of angiogenesis by kigamicin $\mathrm{D}$ we tested the effect of kigamicin $\mathrm{D}$ on various kinds of tumor models.

\section{Human Xenograft Models}

Human lung cancer cells LX-1 and DMS-273 were transplanted into the inguinal area of mice which were treated by the oral administration of kigamicin D. As shown in Fig. 3 and Table 1 administration of $0.75 \mathrm{mg} / \mathrm{kg}$ of kigamicin D showed significant effect on LX-1 tumor by $\mathrm{T} / \mathrm{C} \%$ of $61.3 \%$, but $0.19 \mathrm{mg} / \mathrm{kg}$ was not effective. As shown in Table $2,0.75 \mathrm{mg} / \mathrm{kg}$ of kigamicin D significantly suppressed the growth of DMS-273 tumor by $\mathrm{T} / \mathrm{C} \%$ of $45.3 \%$, but 0.05 and $0.19 \mathrm{mg} / \mathrm{kg}$ showed slight inhibition which was not significant. Against DLD-1 colon cancers kigamicin D had no effect (data not shown.). On the whole, kigamicin D did not have good antitumor activity to these models unlike the activity in human pancreatic xenografts as previously described [2]. 
Table 1 Antitumor effect of kigamicin D on LX-1 tumor in vivo

\begin{tabular}{llccc}
\hline \multicolumn{1}{c}{ Drug } & $\begin{array}{c}\text { Dose } \\
\mathrm{mg} / \mathrm{kg}\end{array}$ & $\begin{array}{c}\text { Tumor weight }(\mathrm{mg}) \\
\text { mean } \pm \text { S.D. }\end{array}$ & $\begin{array}{c}\text { T/C } \\
\%\end{array}$ & $P$ \\
\hline \multirow{2}{*}{ None } & 0 & $2394 \pm 397$ & 100 & \\
Kigamicin D & 0.19 & $2049 \pm 541$ & 85.6 & n.s. \\
& 0.75 & $1468 \pm 363$ & 61.3 & $<0.01$ \\
Adriamycin & 2.5 & $1190 \pm 366$ & 49.7 & $<0.001$ \\
\hline
\end{tabular}

Detail was described in the legend of Fig. 3. On day 28 tumors were removed from mice and tumor weights were measured.

Table 2 Antitumor effect of kigamicin D on DMS-273 tumor in vivo

\begin{tabular}{llccc}
\hline Drug & $\begin{array}{c}\text { Dose } \\
\mathrm{mg} / \mathrm{kg}\end{array}$ & $\begin{array}{c}\text { Tumor weight }(\mathrm{mg}) \\
\text { mean } \pm \text { S.D. }\end{array}$ & $\begin{array}{c}\text { T/C } \\
\%\end{array}$ & $P$ \\
\hline None & 0 & $2593 \pm 600$ & 100 & \\
Kigamicin D & 0.05 & $2202 \pm 609$ & 84.9 & n.s. \\
& 0.19 & $1825 \pm 792$ & 70.4 & n.s. \\
& 0.75 & $1176 \pm 925$ & 45.3 & $<0.05$ \\
Adriamycin & 2.5 & $1170 \pm 813$ & 45.1 & n.s. \\
\hline
\end{tabular}

BALB/c nu/nu female mice were inoculated subcutaneously with $5 \times 10^{6}$ human small cell lung carcinoma DMS-273 cells on day 0 . Kigamicin D was administered orally 5 days/week from day 14 to day 32 . As a positive control adriamycin $(2.5 \mathrm{mg} / \mathrm{kg})$ was administered intraperitoneally on day $14,16,18,20,22,24$, and 26 . On day 35 , tumors were removed from mice and tumor weights were measured.

\section{Syngeneic Tumor Models}

We have observed that kigamicin D strongly increased cellular immunity [5]. In order to study a relationship between antitumor effect and immunomodulating activity of kigamicin D, antitumor activity was tested using some syngeneic tumor models. Effect of kigamicin D on murine colon26 carcinoma cells was shown in Table 3. It had no effect against colon 26 tumor. Against IMC carcinoma cells, sensitive to immunomodulator such as bestatin, a broad dosage range from 0.003 to $12 \mathrm{mg} / \mathrm{kg}$ of kigamicin D increased tumor weight as shown in Fig. 4 and Table 4. The relationship between dosage and tumor growth of IMC carcinoma was an inverted bell-shaped curve. $\mathrm{T} / \mathrm{C} \%$ of 3 , and $12 \mathrm{mg} / \mathrm{kg}$ were more than $200 \%$.

Kigamicin D showed a strong antitumor effect on human tumor xenograft models of pancreatic tumors as previously described [2]. But it does not show good antitumor activity in a broad spectrum of human xenograft tumors and murine syngeneic tumors as described in this paper. Kigamicin
Table 3 Antitumor effect of kigamicin D on murine colon 26 tumor in vivo

\begin{tabular}{lcccc}
\hline \multirow{1}{*}{ Drug } & $\begin{array}{c}\text { Dose } \\
\mathrm{mg} / \mathrm{kg}\end{array}$ & $\begin{array}{c}\text { Tumor weight }(\mathrm{mg}) \\
\text { mean } \pm \text { S.D. }\end{array}$ & $\begin{array}{c}\text { T/C } \\
\%\end{array}$ & $P$ \\
\hline \multirow{2}{*}{ None } & 0 & $7620 \pm 2400$ & 100 & \\
Kigamicin D & 0.012 & $5645 \pm 4161$ & 74 & n.s. \\
& 0.05 & $7967 \pm 1847$ & 105 & n.s. \\
& 0.19 & $5394 \pm 2506$ & 70.8 & n.s. \\
& 0.75 & $7755 \pm 3202$ & 102 & n.s. \\
Furtulon & 30 & $2221 \pm 1928$ & 29.1 & $<0.01$ \\
\hline
\end{tabular}

BALB/c female mice were inoculated subcutaneously with $2 \times 10^{6}$ colon 26 cells on day 0 . Kigamicin D was administered orally 5 days/week from day 1 to day 34. As a positive control, furtulon (5' DFUR, a precursor of 5 -FU converted by thymidine phosphorylase, $30 \mathrm{mg} / \mathrm{kg}$ ) was administered orally by the same schedule as kigamicin D. On day 35 , tumors were removed from mice and tumor weights were measured.

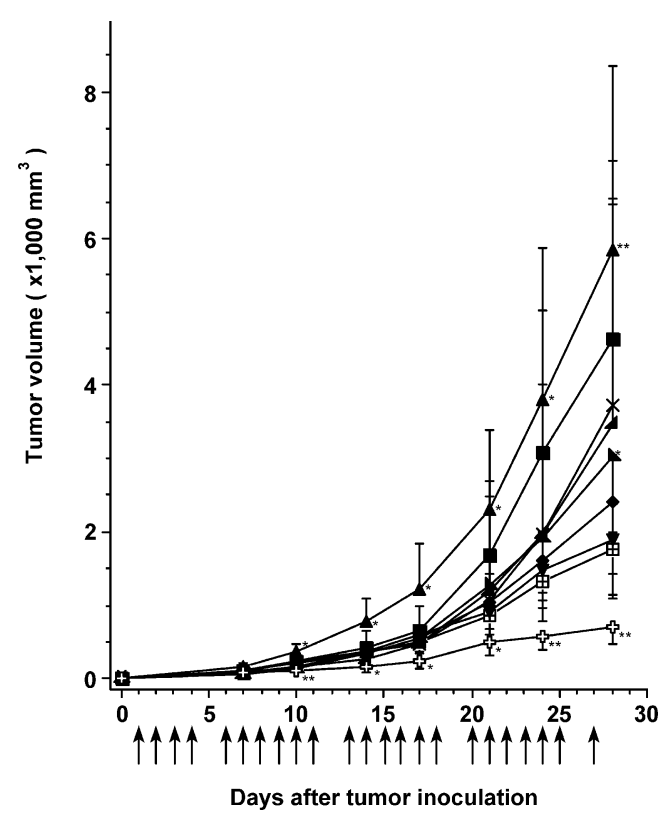

Fig. 4 Effect of kigamicin D on IMC carcinoma.

$\mathrm{CDF}_{1}$ female mice were inoculated subcutaneously with $10^{6}$ IMC carcinoma cells on day 0 . Kigamicin $D$ was administered orally 5 days/week from day 1 to day 27. As a positive control, cyclophosphamide $(100 \mathrm{mg} / \mathrm{kg})$ was administered intraperitoneally on day $1,4,8,11,15,18,22$, and 25 . $P$ values were calculated for Control.

田, Control (none); $\mathbf{\Delta}$, kigamicin D $12 \mathrm{mg} / \mathrm{kg} ; \mathbf{\square}$, kigamicin D $3 \mathrm{mg} / \mathrm{kg}$; , kigamicin D $0.75 \mathrm{mg} / \mathrm{kg} ; \mathbf{\nabla}$, kigamicin D $0.19 \mathrm{mg} / \mathrm{kg} ; \boldsymbol{\Lambda}$,

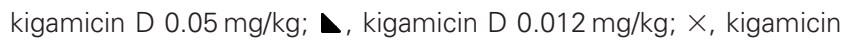
D $0.003 \mathrm{mg} / \mathrm{kg}$; \&, CY $100 \mathrm{mg} / \mathrm{kg} ; * p<0.05 ; * * p<0.01$; vs. control. 
Table 4 Antitumor effect of kigamicin D on murine IMC carcinoma in vivo

\begin{tabular}{lcccc}
\hline Drug & $\begin{array}{c}\text { Dose } \\
\mathrm{mg} / \mathrm{kg}\end{array}$ & $\begin{array}{c}\text { Tumor weight }(\mathrm{mg}) \\
\text { mean } \pm \text { S.D. }\end{array}$ & $\begin{array}{c}\text { T/C } \\
\%\end{array}$ & $P$ \\
\hline None & 0 & $2022 \pm 762$ & 100 & \\
Kigamicin D & 0.003 & $3266 \pm 1833$ & 162 & n.s. \\
& 0.012 & $2888 \pm 635$ & 143 & $<0.05$ \\
& 0.05 & $2893 \pm 1852$ & 143 & n.s. \\
& 0.19 & $2263 \pm 593$ & 112 & n.s. \\
& 0.75 & $2553 \pm 879$ & 126 & n.s. \\
3 & $4049 \pm 1744$ & 200 & $<0.05$ \\
& 12 & $4677 \pm 1361$ & 231 & $<0.01$ \\
Cyclophosphamide & & & \\
& & $740 \pm 211$ & 36.6 & $<0.01$ \\
\hline
\end{tabular}

Detail was described in the legend of Fig. 4. As a positive control, cyclophosphamide $(100 \mathrm{mg} / \mathrm{kg})$ was administered intraperitoneally on day $1,4,8,11,15,18,22$, and 25 . On day 28 , tumors were removed from mice and tumor weights were measured.

D has excellent antitumor effect specific to pancreatic cancers, which may be related to pancreatic cancer-specific microenvironment such as extreme hypovascularity, hypoxia, etc.

The augmentation of tumor growth of IMC carcinoma by kigamicin D may be brought about by immunosuppressive effect or immunological tolerance to the tumor cells. As described elsewhere [5], kigamicin D did not show immunosuppressive activity and any effect on NK cells activity, but showed remarkable increase of cellular immunity. Kigamicin D was thought to act on antigen presenting cells such as dendritic cells and macrophages. The activity on immature dendritic cells may bring about immunological tolerance and the increase of the growth of IMC carcinoma.
Acknowledgment This work was partly supported by Grants-inAid for Research on Cancer from the Ministry of Education, Culture, Sports, Science and Technology of Japan and for the Third-Term Comprehensive 10-Year Strategy for Cancer Control from the Ministry of Health, Labor, and Welfare of Japan.

\section{References}

1. Kunimoto S, Lu J, Esumi H, Yamazaki Y, Kinoshita N, Honma Y, Hamada M, Ohsono M, Ishizuka M, Takeuchi T. Kigamicins, novel antitumor antibiotics. I. Taxonomy, isolation, physico-chemical properties and biological activities. J Antibiot 56: 1004-1011 (2003)

2. Lu J, Kunimoto S, Yamazaki Y, Kaminishi M, Esumi H. Kigamicin D, a novel anticancer agent based on a new antiausterity strategy targeting cancer cells' tolerance to nutrient starvation. Cancer Sci 95: 547-552 (2004)

3. O'Brien J, Wilson I, Orton T, Pognan F. Investigation of the Alamar Blue (resazurin) fluorescent dye for the assessment of mammalian cell cytotoxicity. Eur J Biochem 267: 5421-5426 (2000)

4. Oikawa T, Sasaki M, Inose M, Shimamura M, Kuboki H, Hirano S, Kumagai H, Ishizuka M, Takeuchi T. Effects of cytogenin, a novel microbial product, on embryonic and tumor cell-induced angiogenic responses in vivo. Anticancer Res 17: 1881-1886 (1997)

5. Masuda T, Ohba S, Kawada M, Iijima, Ikeda D, Kunimoto S. Augmentation of Cellular Immunity by Kigamicin D. J Antibiot 59: 215-219 (2006)

6. Oikawa T, Shimamura M. Potent inhibition of angiogenesis by wortmannin, a fungal metabolite. Eur J Phamacol 318: 93-96 (1996)

7. Su JD, Mayo LD, Donner DB, Durden DL. PTEN and phosphatidylinositol 3' kinase inhibitors up-regulate p53 and block tumor-induced angiogenesis: Evidence for an effect on the tumor and endothelial compartment. Cancer Res 63: 3585-3592 (2003) 